The Geneva Papers on Risk and Insurance, 21 (No. 79, April 1996) 204-223

\title{
Long-term Liability and the Choice of Liquidation*
}

\author{
by Robin Mason ** and Timothy Swanson **
}

\section{Introduction}

Many social problems arise due to gaps or loopholes within the existing institutional infrastructure. Under certain conditions, existing institutions may do little to limit the behaviour of the agents that they are intended to regulate, leaving the capacity for profit-taking virtually unconstrained. The potential losses to society that can occur through these loopholes is immense.

Two examples of problems occasioned by gaps within existing regulatory structures are the recent U.S. savings and loan (or thrifts) crisis and the more widespread phenomenon of abandoned waste disposal sites. In the U.S. alone, the thrifts crisis has been estimated to have generated social losses of U.S. $\$ 140$ billion, and the clean-up programme for "orphaned" waste sites U.S. $\$ 100$ billion (see Akerlof and Romer (1993) and Menell (1991)). Nor are the problems confined to the U.S. - the phenomenon of waste site abandonment is something that has occurred across a large number of different jurisdictions. For example, a recent European Union court decision made clear that prohibitions on the international trade in toxic wastes would be allowed to stand as an exception to the Treaty of Rome (the so-called "proximity principle") precisely because of the history of past abuses and abandonments in Europe.

The root of these failures lies in the institution of limited liability and in the range of circumstances under which this institution may be turned to strategic effect. In both of the examples cited above, the shareholders and/or directors of limited liability corporations were able to operate their firms so as to generate immediate benefits and immense but longterm liabilities, and then liquidate the corporation in the interim. The results were profitable for the individuals operating the enterprises but hugely costly for society, something which Akerlof and Romer have termed the "looting" of society.

* We would like to thank the participants of the Sixth Joint Conference between the European Association of Law and Economics and the Geneva Association for the Study of Risk and Insurance, and particularly Paul Fenn, for their comments on an earlier draft of this paper. The usual disclaimer applies. Financial support from the European Commission (project number EV5V-CT94-0382) and the E.S.R.C. (grant number R00429324220) is gratefully acknowledged.

** Nuffield College, University of Oxford and Faculty of Economics and Politics, University of Cambridge, respectively. 
The object of this paper is to identify the circumstances under which such a strategy is available. When does this loophole exist for potential profit-taking to the detriment of society? This is a social problem that exists at the interface between the economic and the institutional realms. The contribution of this paper lies in its identification of the three contributing factors: the institution of limited liability, the productive structure of the industry concerned, and the deferred nature of liabilities within that industry. Together these factors can combine to create a loophole that shareholders of a limited liability corporation can exploit to their gain and society's loss.

The next section of the paper reviews the literature concerning the problem of limited liability and long-term damages, and focuses the enquiry on the phenomenon of strategic liquidation. The third section develops a model that incorporates liquidation as a choice variable, and gives the theoretical conditions under which it is the most attractive option for limited liability shareholders. The fourth section parameterises and simulates this model in order to demonstrate more clearly the economic conditions under which strategic liquidation will occur. The fifth section discusses the policy implications of this analysis. The sixth section concludes that many environmental problems are caused by the intersection of limited liability, industry structure and long-term damages.

\section{Literature review}

In theory, a comprehensive system of liability addresses fully the problem of externalities. Courts act to identify the cause of harm, assess the responsibility of each agent involved, quantify damages to victims, and apportion costs. Injurers face the full (social) cost of their actions, but need pay that cost only after the damage is realised and certain; the correct ex ante incentives are therefore provided. Victims are compensated fully for any damage or injury suffered, and so implicit insurance is provided. For a fuller discussion of these points, see, amongst many others, Cooter (1991).

There are three primary reasons why an ex post liability system fails to live up to this ideal. First, the transactions costs (lawyers' fees; the cost of delays caused by lengthy court proceedings; etc.) can be very large. For example, recent estimates suggest that the total transactions costs of the U.S. Comprehensive Environmental Response Compensation and Liability Act (CERCLA, also known as the Superfund) could exceed U.S. $\$ 44$ billion, out of a total cost of U.S. $\$ 100$ billion (see Menell (1991)). Secondly, attribution of liability requires that the court be able to identify the responsible party. Often, however, there are many injurers (particularly if the damage relates to the environment, where hundreds of firms may be involved in the contamination of a waste disposal site, for example), whose responsibilities may differ. In addition, identification may be hampered by delays between actions and damages, further muddying the waters of causation. It may also be difficult to establish a clear relationship between action and damage, for example because of scientific uncertainty. All of these factors limit the court's ability to assign the correct liability to the correct party; see Swanson (1991). Finally, liability can effectively be truncated because of limited liability and bankruptcy laws; this is known as the "judgement proof" problem, in which responsible parties are unable to pay fully the amount for which they have been found legally liable. The result is that injurers do not consider the full costs of their actions. Shavell (1986) argues that judgement proofness will encourage injurers to engage in risky activities to a socially excessive extent; they will take too little care in undertaking these 
activities; and they will have inadequate incentive to purchase liability insurance. (Note, however, that Shavell's conclusions are challenged by Beard (1990) and Posey (1993), who both argue that injurers may actually take too much care. See section 3.2 of this paper.)

All three failures of the liability system are important; this paper concentrates on the third. Of particular interest is the question: in what situations is the problem of judgement proofness most likely to arise? Ringleb and Wiggins (1990) argue that the problem is most severe when damages are large and long-term. When the expected liability is large, so is the incentive to avoid the liability; when there is a long separation between action and realisation of damage, then the opportunity to avoid the liability also exists.

There are many strategies that can be adopted to exploit the loophole created by limited liability. Roe (1986) (developing earlier ideas of Schwartz (1985)) identifies three: liquidation, asset stripping ${ }^{1}$, and the increased use of subsidiaries and spin-offs. Ringleb and Wiggins (1990) concentrate on the latter, analysing the location of risky activities within small corporations to limit the exposure of assets to liabilities. In another paper (Wiggins and Ringleb (1992)), the same authors argue that liability will cause substitution from physical capital (which can be appropriated by the courts) to labour (which cannot). These strategies take advantage of the dual nature - static and dynamic - of limited liability. Static limitation means that, at any point in time, the liability of shareholders of a corporation is bounded by the assets of the firm. Dynamic limitation means that only damages that have occurred can be presented to the court to be paid from the assets of the injurer. This has two implications : first, the current assets of a firm which is in operation are protected from claims relating to future liabilities; secondly, both the assets and the liabilities of a firm end with its liquidation. Subsidiarisation and capital/labour substitution rely on the static aspect of liability limitation; liquidation on the dynamic; asset stripping on both.

There is substantial anecdotal and empirical evidence of this type of behaviour. The widespread problem of "orphaned" waste disposal sites in the U.S. ; the increase in the number of small corporations operating in hazardous sectors of the U.S. economy (the subject of Ringleb and Wiggins' 1990 article); even the thrifts' crisis in the U.S. (see Akerlof and Romer (1993)) - all are examples of strategic behaviour to avoid liability. On the other hand, Roe concludes that early liquidation will not be used to avoid liability: "the managerial structure of the modern corporation suggests that the liquidation response, although plausible, probably would not be common" (pp. 57-8). One of the aims of this paper is to explore this claim.

Despite the growing literature in this area, several aspects of the problem remain unexplored. First, there has been little formal modelling; consequently, it is unclear which firms/ industries will behave strategically, and in what way, as a result of large future damages. Where a model has been developed (see Wiggins and Ringleb (1992)), the probability of bankruptcy has been treated as a parameter, defeating the object somewhat: the whole point of the analysis is to understand how and when firms will choose to be judgement proof i.e. to make bankruptcy endogenous. Finally, any policy recommendations have concentrated on amendments to ex post liability systems - the very cause of the problem in the first place (see, for example, Hansmann and Kraakman (1991)). This paper has two objectives, therefore: first, to identify what liability-evading strategy (if any) will be followed by which

\footnotetext{
"Roe refers to this option as "delay in reorganisation", which he describes as "keep[ing] the firm going outside of bankruptcy and consign[ing] it to a slow, bleeding, perhaps decade-long rundown", (p.5).
} 
type of firm/industry in what circumstance, using a model in which capital levels (and therefore, implicitly, bankruptcy) and care are both choice variables; secondly, to assess the need for ex ante instruments to complement a system of ex post liability.

\section{A model of looting}

In this section, a simple two-period discrete-time model is developed in order to analyse the strategic behaviour of firms faced with a large liability that might occur at some distant future date. Two key features of the model are firms' ability to influence the occurrence of both bankruptcy (by choosing levels of capital and dividend payments) and the liability (by expending on care). The model is used to establish three results:

1. In specific circumstances, shareholders faced with a large future liability will liquidate their firm before the liability realise; this is referred to as the looting strategy (see section 3.2 , case 2 ).

2. In general, limitation of liability distorts shareholders' capital and care choices in ways that are difficult to predict theoretically (see section 3.2, case 1); which outcome results is an empirical question.

3. Parameterisation of the model suggests that incentive for looting will be greatest in industries characterised by low marginal productivity of capital, high levels of sunk capital, and ineffective care expenditure (see section 4).

The model has three dates: $t=0,1$ and 2. As in Wiggins and Ringleb (1992), the twoperiod framework captures the long delay between the firm's initial actions and the occurrence of any resulting damage. At $t=0$, shareholders make an initial investment in a firm of $K_{0}$. For simplicity, assume that capital-does not depreciate, and that no further investment is made after this date. The capital yields output at $t=1$ according to a production function $f_{1}$, so that period-1 output is $f_{1}\left(K_{0}\right)$. From this output are paid dividends $\Delta_{1}$ and expenditure $E$ on preventative care (the role of which is explained further below). The shareholders also decide how much of the capital to "scrap" - that is, remove from productive use and sell for a value of $\phi_{1}(K)$; the amount of capital scrapped at $t=1$ is denoted $K_{1}$. Any cash (output and scrap value not spent in the form of dividends or care expenditure) is held on reserve at the period- 1 interest factor, $\delta_{1}=1+r_{1}$. At $t=2$, the remaining stock of capital $K_{0}-K_{1}$ yields output $f_{2}\left(K_{0}-K_{1}\right)$. As a consequence of the firm's production, a damage $D$ occurs (this damage might be the cost of cleaning up a disposal site contaminated by the hazardous waste generated by the firm; or the compensation demanded by employees of the firm who have suffered injury as a result of their work). The damage realises with probability $p(E)$, where $0<p \leq 1$. Increased care expenditure decreases the probability of the damage occurring, so that $p^{\prime}(E)<0$; but it does so at a decreasing rate $\left(p^{\prime \prime}(E)>0\right)$. If the firm has spent nothing on care, then the damage occurs with certainty i.e. $p(0)=1$. If the firm "survives" this damage (is able to meet the full amount of the damage without selling its entire assets), it carries on its production in perpetuity, distributing the whole of its output as dividends and making no further changes to its capital ${ }^{2}$. This flow of dividends is represented as a lump-sum paid at $t=2$, equal to $\frac{\sum_{t=3}^{\infty} f_{t}(K)}{\Pi_{t=3}^{\infty} \delta_{t}}$. The numerator is the total output produced

2 This somewhat artificial arrangement should be seen just as a convenient way to "close" the model; no major conclusions depend on it. 
by the firm which has capital $K$ remaining after paying the damage; the denominator discounts this total flow back to $t=2$ values, using the period- $t$ discount factor $\delta_{t}$. The price of the firm's output is normalised to 1 ; the cost of capital is $\omega$.

The functions $f_{1}, f_{2}, \phi_{1}$ and $\phi_{2}$ are all strictly increasing and concave in their arguments (this ensures that the first-order conditions developed below are both necessary and sufficient to find the optima required). The functions $\phi_{i}$ are such that $\phi_{i}(K)<K-$ that is, the full value of capital cannot be gained on scrapping. There are many reasons why this might be the case; the most important for the analysis of this paper is that capital might be in some way specific to the firm i.e. sunk.

\section{I. The social optimum}

The socially optimal levels of capital, dividends and care expenditure are those levels that maximise total benefits minus total expected costs, discounted to $t=0$ values $^{3}$ :

$$
\begin{aligned}
V^{\mathrm{So}} & =\max _{\left\{K_{0}, K_{1}, \Delta_{1}, E\right\}}-\omega K_{0}+\frac{\Delta_{1}}{\delta_{1}}+\frac{\mathrm{E}\left[\Delta_{2}\right]}{\delta_{1} \delta_{2}} \text { where } \\
\Delta_{2} & =f_{2}\left(K_{0}-K_{1}\right)+\delta_{2}\left(f_{1}\left(K_{0}\right)+\phi_{1}\left(K_{1}\right)-\Delta_{1}-E\right)-D+\frac{\sum_{t=3}^{\infty} f_{t}\left(K_{0}-K_{\mathrm{L}}\right)}{\Pi_{t=3}^{\infty} \delta_{t}} \\
& \left.=\frac{\sum_{t=3}^{\infty} f_{t}\left(K_{0}-K_{1}-\phi_{2}^{-1}\left(D-\left(f_{2}\left(K_{0}-K_{1}\right)+\delta_{2}\left(f_{1}\left(K_{0}\right)+\phi_{1}\left(K_{1}\right)-\Delta_{1}-E\right)\right)\right)\right.}{\Pi_{t=3}^{\infty} \delta_{t}}\right\} \text { w.p. } p(E), \\
\Delta_{2} & =f_{2}\left(K_{0}-K_{1}\right)+\delta_{2}\left(f_{1}\left(K_{0}\right)+\phi_{1}\left(K_{1}\right)-\Delta_{1}-E\right)+\frac{\sum_{t=3}^{\infty} f_{t}\left(K_{0}-K_{1}\right)}{\Pi_{t=3}^{\infty} \delta_{t}^{-}} \quad \text { w.p. }(1-p(E)) .
\end{aligned}
$$

where "w.p." stands for "with probability". $\Delta_{2}$ can take three values, depending on whether the damage occurs or not. In the event that the damage occurs, two cases are possible. First, the damage may be sufficiently small that its (monetised) value can be met from flow revenues (period-2 output and reserves plus interest from the first period) without the social planner resorting to the scrapping of a portion of the firm's capital; this is the first definition of $\Delta_{2}$ given above. The second case is, of course, the converse - the damage $D$ is so large that, in addition to flow revenues, a portion of the capital stock must be sold to pay the liability. In this case, the firm's second period capital $\left(K_{0}-K_{1}\right)$ is reduced by the amount of capital that must be scrapped in order to meet the liability (say, $K_{2}$ ). $K_{2}$ depends on three factors: (i) the size of the damage ; (ii) the amount of flow revenues (and hence, with (i), the remaining part of the liability to be paid for once flow revenues have been exhausted); and (iii) the value of capital which is lost on scrapping. This last factor explains the presence of the term $\phi^{-1}($.$) (where " -1$ " denotes an inverse function). $\phi^{-1}(C)$ is the amount of capital that would have to be scrapped in order to pay a cost $C$ (ignoring, for the moment, flow revenues). For example, if $\phi(K)=b K$, then the amount of capital that would have to be scrapped would be equal to $C / b$. So capital left after the liability has been paid is period-2 capital $K_{0}-K_{1}$ minus the amount that must be scrapped to cover fully the liability, taking into account the sunk nature of capital.

${ }^{3}$ Strickly speaking, the constraint that period-1 payments cannot exceed period-1 returns must be considered : $\Delta_{1}+E \leq f_{1}\left(K_{0}\right)+\phi\left(K_{1}\right)$. It turns out that this constraint does not bind in the socially optimal case. 
The argument of this paper is that there are strategies available to limited liability shareholders that earn greater returns than socially optimal behaviour - even in the most favourable conditions for the latter. In order to show this, the analysis will concentrate on the case where the optimally-run firm can meet the damage payment from its revenue flows. ${ }^{4}$ Therefore:

$$
V^{\text {SO }}=\max _{\left\{K_{0}, K_{1}, E\right\}}\left[\begin{array}{l}
\frac{f_{2}\left(K_{0}-K_{1}\right)+\delta_{2}\left(f_{1}\left(K_{0}\right)+\phi_{1}\left(K_{1}\right)-E\right)-p(E) D}{\delta_{1} \delta_{2}} \\
+\frac{\sum_{t=3}^{\infty} f_{t}\left(K_{0}-K_{1}\right)}{\delta_{1} \delta_{2} \Pi_{t=3}^{\infty} \delta_{t}}-\omega K_{0} .
\end{array}\right]
$$

The first-order conditions for the social optimum are :

$$
\begin{aligned}
& \delta_{2} f_{1}^{\prime}\left(K_{0}^{\mathrm{SO}}-K_{1}^{\mathrm{SO}}\right)+f_{2}^{\prime}\left(K_{0}^{\mathrm{SO}}-K_{1}^{\mathrm{SO}}\right)+\frac{\sum_{t=3}^{\infty} f_{t}^{\prime}\left(K_{0}^{\mathrm{SO}}-K_{1}^{\mathrm{SO}}\right)}{\Pi_{t=3}^{\infty} \delta_{t}}=\delta_{1} \delta_{2} \omega, \\
& \delta_{2} \phi_{1}^{\prime}\left(K_{1}^{\mathrm{sO}}\right)-f_{2}^{\prime}\left(K_{0}^{\mathrm{SO}}-K_{1}^{\mathrm{SO}}\right)+\frac{\sum_{t=3}^{\infty} f_{t}^{\prime}\left(K_{0}^{\mathrm{SO}}-K_{1}^{\mathrm{SO}}\right)}{\Pi_{t=3}^{\infty} \delta_{t}} \leq 0, K_{1}^{\mathrm{SO}} \geq 0, \\
& \Delta_{1}^{\mathrm{so}}=0 \text {, } \\
& -\frac{p^{\prime}\left(E^{\mathrm{SO}}\right) \underline{D}}{\delta_{2}}=1 \text {. }
\end{aligned}
$$

Primes denote first-order derivatives. Interior solutions have been assumed for $K_{0}^{\text {so }}$ and $E^{\text {so }}$. The possibility of a corner solution has been allowed for $K_{1}^{\text {so }}$, so that equation (3) holds with complementary slackness.

These conditions express the usual economic marginal equalities for an optimum. Equation (2) says that the initial capital level will be chosen so that the return from the marginal unit of that capital (equal to output in period 1 plus output in period 2 plus the continuation value of the firm, shown on the left hand side of the equation) equals its cost (i.e. $\omega$, shown on the right-hand side). Likewise, equation (5) shows that the socially optimal level of care expenditure is such that the marginal cost ( 1 , on the right-hand side) equals the marginal benefit from a reduction in the probability of the damage occuring (shown on the left-hand side; remember that $p^{\prime}(E)<0$ ). Finally, period-1 dividends are equal to zero - the social planner is indifferent to the timing of payments, and waits until the second period to extract dividends from the firm. ${ }^{5}$

4 This means that the following condition holds:

$$
D<f_{2}\left(K_{0}^{\mathrm{SO}}-K_{1}^{\mathrm{SO}}\right)+\delta_{2}\left(f_{1}\left(K_{0}^{\mathrm{SO}}\right)+\phi\left(K_{1}^{\mathrm{SO}}\right)-\Delta_{1}^{\mathrm{SO}}-E^{\mathrm{SO}}\right) .
$$

Whether this condition holds or not is, in part, endogenous, since it involves the choices of capital, dividends and care, as well as the exogenous value $D$. This objection can be dealt with theoretically by incorporating equation (1) as a constraint in the social planner's optimisation problem; to keep the analysis clear, this is not done (implicitly, it is assumed that the constraint does not bind). In the parameterisation of the model in section 4 , the parameter values are chosen so equation (1) holds.

5 This feature is a consequence of the assumption that no further investment occurs after $t=0$. This simplification serves to contrast the behaviour of the social planner and a limited liability corporation. 


\subsection{Limited liability}

Now consider the choices of a limited liability corporation, faced with strict liability for the damage (should it occur), and unwilling to purchase full insurance. The objective of the firm is to ${ }^{6}$ :

$$
\begin{aligned}
& V^{\mathrm{LL}}=\max _{\left\{K_{0}, K_{1}, \Delta_{1}, E\right\}}-\omega K_{0}+\frac{\Delta_{1}}{\delta_{1}}+\frac{\mathrm{E}\left[\Delta_{2}\right]}{\delta_{1} \delta_{2}} \\
& \Delta_{1}+E \leq f_{1}\left(K_{0}\right)+\phi_{1}\left(K_{1}\right) \\
& \left.\begin{array}{rl}
\Delta_{2} & =\max \left[0, f_{2}\left(K_{0}-K_{1}\right)+\delta_{2}\left(f_{1}\left(K_{0}\right)+\phi_{1}\left(K_{1}\right)-\Delta_{1}-E\right)-D+\frac{\sum_{t=3}^{\infty} f_{t}\left(K_{0}-K_{1}\right)}{\Pi_{t=3}^{\infty} \delta_{t}}\right] \\
& =\max \left[0, \frac{\sum_{t=3}^{\infty} f_{t}\left(K_{0}-K_{1}-\phi_{2}^{-1}\left(D-\left(f_{2}\left(K_{0}-K_{1}\right)+\delta_{2}\left(f_{1}\left(K_{0}\right)+\phi_{1}\left(K_{1}\right)-\Delta_{1}-E\right)\right)\right)\right.}{\Pi_{t=3}^{\infty} \delta_{t}}\right]
\end{array}\right\} \text { w.p. } p(E), \\
& \Delta_{2}=f_{2}\left(K_{0}-K_{1}\right)+\delta_{2}\left(f_{1}\left(K_{0}\right)+\phi_{1}\left(K_{1}\right)-\Delta_{1}-E\right)+\frac{\sum_{t=3}^{\infty} f_{t}\left(K_{0}-K_{1}\right)}{\Pi_{t=3}^{\infty} \delta_{t}} \quad \text { w.p. }(1-p(E)) \text {. }
\end{aligned}
$$

The second line of this expression shows the irreversibility of capital investment - period-1 payments cannot exceed output plus the scrap value in that period. The third and fourth lines show the effect of limited liability. If the damage does occur, then the shareholders gain either the net returns of the firm - that is, output plus reserves interest plus continuation value, minus the cost of the damage, $D$ - or zero, whichever is the greater. (As in the social optimum, there are two cases according to whether period- 2 flow revenues are sufficient to pay the damage - the third line above - or whether some capital must be sold to meet the liability - line four.) In the case of zero return, the cost of the damage actually exceeds the period- 2 value of the firm. Shareholders, however, are protected by limited liability, and so cannot be forced to pay out more than the current worth of the firm their return is bounded below by zero. In the event that the damage does not occur, the firm's returns are period- 2 output plus interest earned on reserves from the first period plus the continuation value (infinite stream of dividends). The probability of this outcome is $(1-p(E))$.

The form of the firm's profit function shows that there are two cases to be considered.

CASE 1: Maximum value requires that the firm be kept in operation for both period; in this case:

$$
\max _{\left\{K_{0}\right\}} \frac{f_{1}\left(K_{0}\right)+\phi_{1}\left(K_{0}\right)}{\delta_{1}}<\max _{\left\{K_{0}, K_{1}, E\right\}} \frac{f_{2}\left(K_{0}-K_{1}\right)+\delta_{2}\left(f_{1}\left(K_{0}\right)-E\right)+\frac{\sum_{t=3}^{\infty} f_{t}\left(K_{0}-K_{1}\right)}{\Pi_{t=3}^{\infty} \delta_{t}}-p(E) D}{\delta_{1} \delta_{2}} .
$$

\footnotetext{
${ }^{6}$ It is assumed that the shareholders are risk neutral with respect to the firm's returns, so that they care only about the expected returns of the firm. Also, any conflict between management and shareholders is ignored in this analysis - managers are assumed to act solely in the interests of the shareholders of the company. In subsequent discussions, the words "shareholders" and "firm" are used interchangeably.
} 
Condition (6) will be explained further in case 2 below. There are two further possibilities to consider, corresponding to whether the size of the damage $D$ is larger than the firm's second period assets. If it is not, then the firm's profit maximisation problem is the same as the social optimum, and the firm's choice of capital, dividends and care expenditure are given by equations (2)-(5). If the damage is sufficiently large, however, the profit maximisation problem becomes :

$\mathrm{V}^{\mathrm{JP}}=\max _{\left\{K_{0}, K_{1}, \Delta_{1}, E\right\}}\left[\begin{array}{l}\frac{\Delta_{1}}{\delta_{1}}+\frac{(1-p(E))}{\delta_{1} \delta_{2}}\left[\frac{\sum_{t=3}^{\infty} f_{t}\left(K_{0}-K_{1}\right)}{\Pi_{t=3}^{\infty} \delta_{t}}\right]-\omega K_{0} \\ +\frac{(1-p(E))}{\delta_{1} \delta_{2}}\left[f_{2}\left(K_{0}-K_{1}\right)+\delta_{2}\left(f_{1}\left(K_{0}\right)+\phi_{1}\left(K_{1}\right)-\Delta_{1}-E\right)\right]\end{array}\right]$

In this case, the first-order conditions for profit maximisation are :

$$
\begin{aligned}
& \left(1-p\left(E^{\mathrm{JP}}\right)\right)\left[\delta_{2} f_{1}^{\prime}\left(K_{0}^{\mathrm{JP}}\right)+f_{2}^{\prime}\left(K_{0}^{\mathrm{JP}}-K_{1}^{\mathrm{JP}}\right)+\frac{\sum_{t=}^{\infty} \frac{3}{\prime}\left(K_{0}^{\mathrm{JP}}-K_{1}^{\mathrm{JP}}\right)}{\Pi_{t=3}^{\infty} \delta_{t}}\right]=\delta_{1} \delta_{2} \omega, \\
& \delta_{2} \phi_{1}^{\prime}\left(K_{1}^{\mathrm{JP}}\right)-f_{2}^{\prime}\left(K_{0}^{\mathrm{JP}}-K_{1}^{\mathrm{JP}}\right)-\frac{\sum_{t=3}^{\infty} f_{t}^{\prime}\left(K_{0}^{\mathrm{JP}}-K_{1}^{\mathrm{JP}}\right)}{\Pi_{t=3}^{\infty} \delta_{t}} \leq 0, K_{1}^{\mathrm{JP}} \geq 0, \\
& \Delta_{1}^{\mathrm{JP}}=f_{1}\left(K_{0}^{\mathrm{JP}}\right)-E^{\mathrm{JP}}+\phi_{1}\left(K_{1}^{\mathrm{JP}}\right), \\
& -p^{\prime}\left(E^{\mathrm{JP}}\right)\left[f_{2}\left(K_{0}^{\mathrm{JP}}-K_{1}^{\mathrm{JP}}\right)+\frac{\sum_{t=3}^{\infty} f_{t}^{\prime}\left(K_{0}^{\mathrm{JP}}-K_{1}^{\mathrm{JP}}\right)}{\Pi_{t=3}^{\infty} \delta_{t}}\right]=\delta_{2}\left(1-p\left(E^{\mathrm{JP}}\right)\right)
\end{aligned}
$$

Of these four first-order conditions, only one - equation (8) - is the same as its socially optimal counterpart. The rest are distorted by the fact that the firm faces only that part of the second period problem in which it is solvent, so that in period 2, either marginal benefits, or marginal costs, or both are multiplied by a factor of $\left(1-p\left(E^{\mathrm{JP}}\right)\right)$. This case has been termed the "judgement proof problem" by Shavell (1986); it will not be analysed in detail here. Shavell made the intuitively reasonable argument that reduced stakes (as indicated by comparing equations (2) and (7), and (5) and (10)) would increase activity levels and reduce care. Beard (1990) and Posey (1993) have noted that this is not necessarily the case, because the effective cost of care is reduced by limited liability, as well as the effective benefit (since the level of liability is bounded by the level of retained assets), and the effective cost of capital is increased. ${ }^{7}$ Therefore, the impact of "judgement proofness" on care and activity level decisions is an empirical question. The only theoretical conclusion that can be drawn is that the story is more complicated than suggested by Shavell.

7 There are a few differences between this model and those presented by the authors cited. First, the authors use a single-period model, and hence they have no analysis of capital scrapping. This means that they cannot consider the looting strategy that will be analysed below. Secondly, they treat the probability of bankruptcy as exogenous, and so do not model shareholders' choice between the alternative strategies - socially optimal behaviour, judgement proofness and looting - available to them. Despite these differences, several of the results in Beard and Posey (in particular, the theoretical indeterminacy of capital and care expenditures) are similar. 
The next case is the focus of this paper:

CASE 2 ("Looting"): Maximum value can be extracted from the firm by running it for 1 period, and scrapping it entirely at $t=1$; i.e. :

$\max _{\left\{K_{0}\right\}} \frac{f_{1}\left(K_{0}\right)+\phi_{1}\left(K_{0}\right)}{\delta_{1}}>\max _{\left\{K_{0}, K_{1}, E\right\}} \frac{f_{2}\left(K_{0}-K_{1}\right)+\delta_{2}\left(f_{1}\left(K_{0}\right)-E\right)+\frac{\sum_{t=3}^{\infty} f_{i}\left(K_{0}-K_{1}\right)}{\Pi_{t=3}^{\infty} \delta_{t}}-p(E) D}{\delta_{1} \delta_{2}}$.

The following profit-maximisation conditions hold:

$$
\begin{aligned}
f_{1}^{\prime}\left(K_{0}^{\mathrm{L}}\right)+\phi_{1}^{\prime}\left(K_{0}^{\mathrm{L}}\right) & =\delta_{1} \omega, \\
K_{1}^{\mathrm{L}} & =K_{0}^{\mathrm{L}}, \\
\Delta_{1} & =f_{1}\left(K_{0}^{\mathrm{L}}\right)+\phi_{1}\left(K_{0}^{\mathrm{L}}\right), \\
E^{\mathrm{L}} & =0 .
\end{aligned}
$$

In this case, shareholders' returns are maximised by extracting all value from the firm at $t=1$, leaving no assets to meet the damages that might occur in the second period. The condition in equation (11) essentially says just this - if more value can be extracted in one period than by keeping the firm operational, then shareholders will opt for an "looting" strategy. This strategy involves choosing initial capital to maximise period-1 dividends (equations (12) and (14)), while undertaking no care (equation (15)), and liquidating the firm at $t=1$ (equation (13)).

This conclusions is qualitatively different from that of Shavell, in which an exogenous probability of "judgement proofness" distorts incentives. In this case, shareholders choose to be judgement-proof - it is not that there is the possibility of bankruptcy, which distorts shareholders' incentives; it is that the owners of the firm will ensure with probability equal to one that there are no assets to meet the liability in the second period. The outcome may be similar in the two models (there are insufficient assets to pay damages, and too little care is taken); but the direction of causation is radically different. Akerlof and Romer (1993), in their paper on crises in financial institutions, refer to this phenomenon as the economics of looting. In their words:

... the normal economics of maximising economic value is replaced by the topsy-turvy economics of maximising current extractable value, which tends to drive the firm's economic net worth deeply negative. ... Because of [the] large disparity between what the owners can capture and the losses that they create, we refer to bankruptcy for profit as looting.

pp. 2-3. 
There are, therefore, three sources of inefficiency in this case. First, the firm's choice of production process is distorted towards projects which yield high payoffs in the first period; some of these projects will have highly negative present discounted social values (see the next section). Secondly, no preventative care is undertaken - the firm knows that it will receive no benefit from taking care, and so rationally makes no expenditure. Finally, there are no assets in the second period to pay for any damages that might arise as a result of the firm's activities (this is a problem if the liability system is intended to act as a significant source of social insurance).

\section{The conditions under which shareholders will loot}

The previous section gave the theoretical conditions under which looting will be the most profitable strategy for limited liability shareholders. In this section, the discrete-time model that has been developed is parameterised in order to answer the question: what types of industries will pursue which strategy?

\subsection{Parameterisation of the model}

The following simple functional forms will be used:

FUNCTIONAL FORM 1: The production function is stationary and Cobb-Douglas i.e. $f_{1}(K)=f_{2}(K)=f_{t}(K)=K^{a}$, where $0<a<1$.

FUNCTIONAL FORM 2: The capital scrapping function is linear i.e. $\phi_{1}(K)=b K$, where $0<b<1$.

FUNCTIONAL FORM 3: The probability of damage occurence function is iso-elastic i.e. $p(E)=(1+E)^{-\epsilon}$.

Figures 1-4 depict the solutions graphically, showing their dependence on the underlying parameters $a$ (the marginal productivity of capital), $b$ (the extent to which capital is sunk i.e. the fraction of the capital's value that can be recouped by shareholders on scrapping), and $\in$ (the elasticity of the damage probability function, which measures the firm's ability to influence the likelihood of the damage occuring). Figures 1-3 show the variations of the value functions $V^{\mathrm{so}}, V^{\mathrm{L}}$ and $V^{\mathrm{JP}}$ with changes in the three parameters. Figure 4 shows the values of $a$ and $b$ for which $V^{\text {so }}$ is greater than $V^{\mathrm{L}}$, and vice versa.

There are two other important parameters in the model. $D$, the size of the damage, is set equal to 5 ; this value is smaller than period- 2 flow revenues in the socially optimal case (as required by condition (1)), but nevertheless represents a large liability (in the examples of this section, it is approximately $25-100 \%$ of the assets of the firm managed by the social planner, depending on the parameter values used). $r$, the discount rate, is set equal to $78 \%$; with an annual interest rate of $6 \%$, this means that each period lasts about ten years, and that therefore the liability occurs after twenty years. Both $D$ and $r$ are set, therefore, to satisfy Ringleb and Wiggins' condition that the liability be large and long-term for strategic behaviour to be worthwhile. ${ }^{8}$

8 The final parameter value used in the simulation is $\omega=0.4$. 
Figure 1: Profits from alternative strategies with changes in model parameters

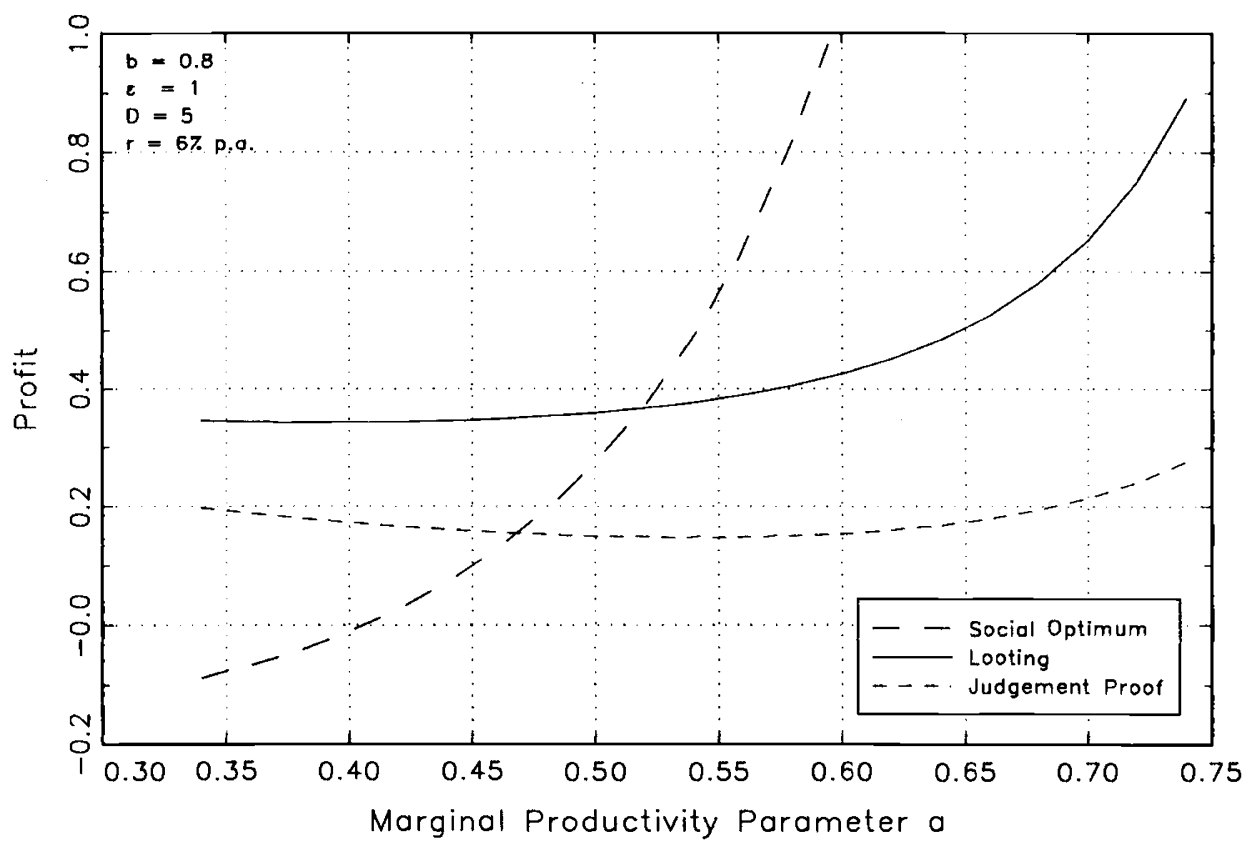

Figure 1 shows the dependence of $V^{\mathrm{so}}, V^{\mathrm{L}}$ and $V^{\mathrm{JP}}$ on the marginal productivity parameter $a$ (with the parameters $b$ and $\epsilon$ set equal to 0.8 and 1 respectively). $V^{\text {so }}$ and $V^{\mathrm{L}}$ both increase with $a$, as is to be expected. ${ }^{9}$ For the values of $b$ and $\epsilon$ chosen, $V^{\mathrm{L}}$ lies above $V^{\mathrm{JP}}$ for all values of $a$ : a shareholder protected by limited liability will prefer to loot than choose the JP strategy. $V^{\mathrm{L}}$ is positive for all $a$ (it can never be negative), but $V^{\text {so }}$ is less than zero for $a$ less than about 0.41 . For marginal productivity is this region, the social costs of the firm's activities outweigh the social benefits, and the planner would not choose to operate the firm. Shareholders avoid part of the costs of their activities, however, and the firm has positive value under the $\mathrm{JP}$ and $\mathrm{L}$ strategies.

Figure 2 carries out the same analysis, but with respect to the sunk capital parameter $b$. Strategies SO and JP do not involve scrapping of any capital $\left(K_{1}\right.$ equals zero in both, and, due to condition (1), the social planner need not scrap capital in the second period to pay for the damage); the profit from these strategies is therefore constant with respect to

${ }^{9}$ The shape of $V^{\mathrm{JP}}$ is more difficult to understand. Figure 1 shows that, in this example, the profit from the judgement proof strategy decreases over a lower range of $a$, increasing only for $a$ greater than 0.525 . This counter-intuitive result is an artifact of the model - for low $a$, the optimal capital level $K_{0}^{\mathrm{JP}}$ is less than 1 , so that an increase in $a$ decreases output $\left(K_{0}^{\mathrm{JP}}\right)^{a}$. The same problem does not arise in the case of the SO and L strategies, however. 
changes in $b . V^{\mathrm{l}}$ increases with $b$, however - profits from looting, in which all capital is scrapped after one period, increase as the value loss to scrapping decreases. Figure 2 shows that for $b$ sufficiently large (greater than 0.86 , with $a=0.525$ and $\epsilon=1$ - that is, less than $15 \%$ of the value capital lost on its scrapping), the profit from looting exceeds that from socially optimal behaviour; for $b$ lower than this (i.e. higher levels of sunk capital), $V^{\mathrm{L}}$ drops below $V^{\text {so }}$. (With the parameter values used, $V^{\mathrm{JP}}$ lies below the returns from the other two strategies.)

Figure 3 shows how returns vary with the elasticity of the damage probability function $\epsilon$; $a$ and $b$ are fixed at 0.5 and 0.8 in this figure. $V^{\mathrm{L}}$ is independent of $\epsilon$, since the looting strategy involves no care expenditure. The signs of both $V^{\mathrm{so}}$ and $V^{\mathrm{L}}$ depend on the parameter value. For low $\epsilon$, both are negative; for higher $\epsilon$, both are positive; and for still higher $\epsilon$, both exceed the return to looting. This analysis echoes that to figure 1 - for low parameter values (i.e. low productivity of capital or highly ineffective care expenditures), production has negative social value, and the social planner would not choose to operate the firm. For higher values, $V^{\text {so }}$ becomes positive, and may exceed the returns from either looting (or the judgement proof strategy), for high enough $a$ and $\epsilon$.

Figure 2: Profits from alternative strategies with changes in model parameters

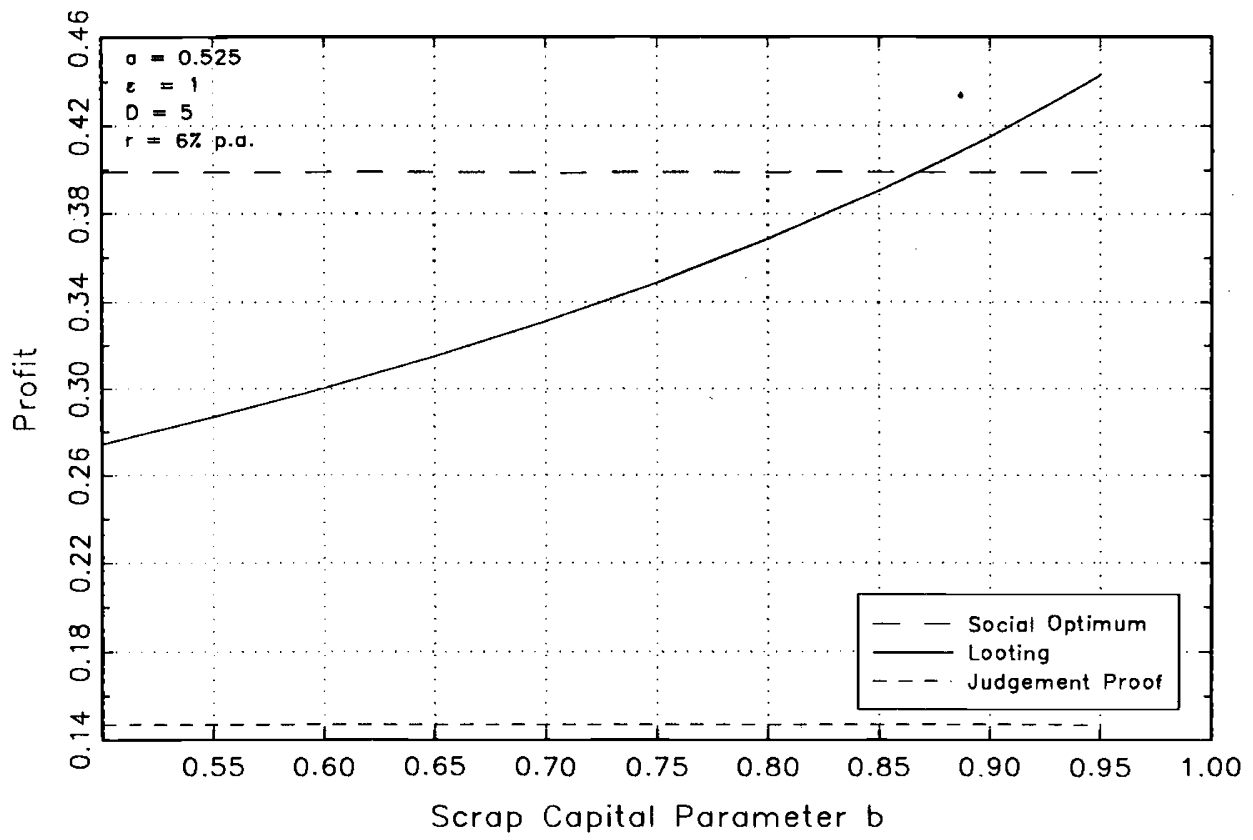


Figure 3: Profits from alternative strategies with changes in model parameters

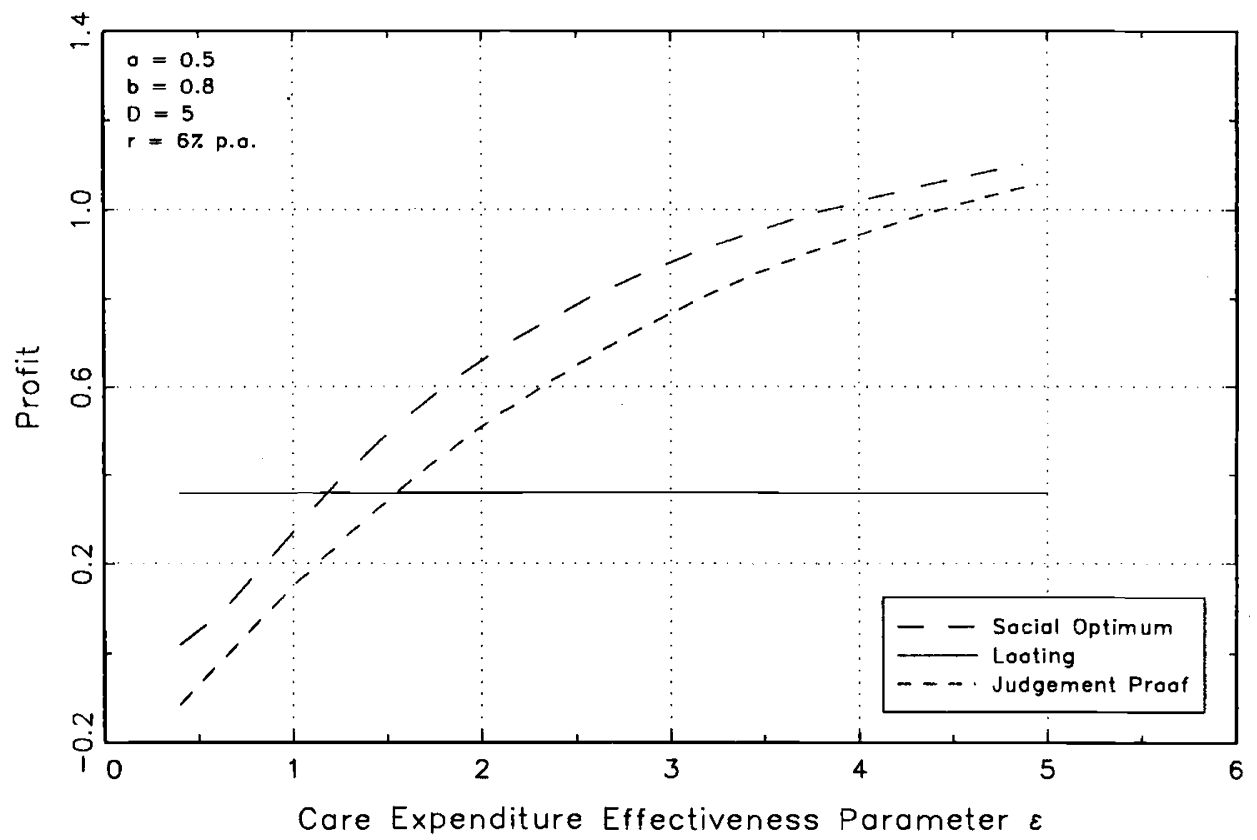

The figures indicate that the parameter values define three regions. The relevance of these three regions lies in their policy implications, to be discussed in the next section. In the first region (I), socially optimal behaviour is the most attractive strategy i.e. $V^{\text {so }}$ is greater than both $V^{\mathrm{L}}$ and $V^{\mathrm{JP}}$. In figure 1 , this region lies to right of $a=0.52$; in figure 2 , it is to the left of $b=0.87$; and in figure 3, it is to the right of $\epsilon=1.2$. The second region (II) is defined by $V^{\mathrm{sO}}>0$, but less than $V^{\mathrm{L}}$ (or $V^{\mathrm{JP}}$, whichever is the greater). In this region, the firm has positive social value, but shareholders will choose looting over socially optimal behaviour. Region II in figure 1 lies between the values of 0.41 and 0.52 for $a$; in figure 2, it is defined by any value of $b$ less than 0.87 ; and in figure 3 , it lies between $\epsilon=1.2$. Finally, region III has $V^{\text {SO }}<0$ - the firm has negative social value. In figure 1 , this region lies to the left of $a=0.41$; figure 2, as drawn, does not have a region III (although with other parameter values, it might); region III lies to the left of $\epsilon=0.4$ in figure 3 .

Figure 4 shows the pairs of $(a, b)$ parameter values for which socially optimal behaviour yields the greatest return, and the values for which looting is best for shareholders. $(\epsilon=1$, $D=5$ and $r=6 \%$ per annum in this figure). The region to the north-west of the upwardsloping line is the set of values in which $V^{\text {so }}>V^{\mathrm{L}}$ : this region corresponds to highly productive (high $a$ ) and highly sunk (low $b$ ) capital (as figures 1 and 2 suggest). Conversely, the region to the south-east favours looting - marginal productivity is low, as is the degree to which capital is sunk. It is clear from the plot that regions II and III occupy a significant part of the total space: $V^{\mathrm{L}}$ is greater than $V^{\mathrm{so}}$ for many parameter values, and the figure suggests that looting will hardly be an exception. Moreover, the frontier marked on the figure will shift as $\in, D$ and $r$ change. Higher $D$ and $r$-larger and longer- 
term damages - or lower $\epsilon$ - less effective care expenditure - will cause the frontier to move to the north-west, so that the region in which looting is optimal increases in range (and vice versa).

Figure 4: Region in which looting is profitable

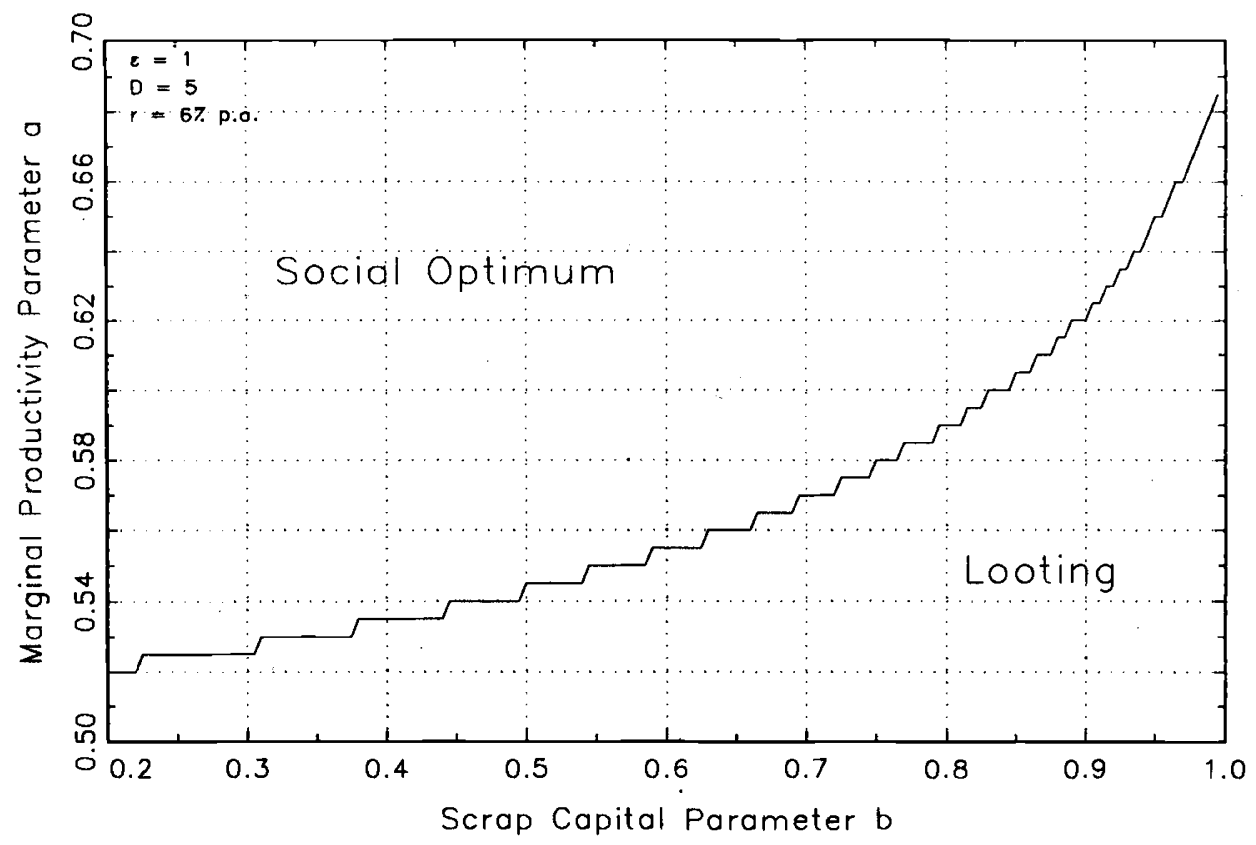

\subsection{The meaning of the parameter: Examples}

This section gives examples to explain further the role of the three parameters - the productivity of capital, the degree to which it is sunk, and the effectiveness of care expenditures in reducing the probability of damage. The objective is to make concrete some of the results obtained in the preceding sections, in order to inform the policy discussion that follows in section 5 .

\subsubsection{The importance of fixed capital investments}

Capital productivity measures the returns that can be generated from a stock of capital. Its relevance is two-fold. First, it is a major determinant of the returns to remaining within an industry (as opposed to liquidating early). Secondly, it measures the extent to which firms will invest in fixed, rather than mobile (i.e. labour) capital; this in turn influences the relative attractiveness of the judgement proof strategy (see Wiggins and Ringleb (1992)).

A firm that operates in region I will inake its choices in a socially optimal fashion despite the availability of limited liability. This is most likely to be the case when capital productivity $(a)$ is high (other things being equal). In this case, the industry will be capital intensive, generating high returns on that capital. This results in the vesting of the firm within the industry, since its return from maintaining its current capital stock operational is far greater 
than the return from liquidating to avoid prospective liabilities. This corporation will therefore be willing to provide for future - even substantial - liabilities in order to remain in operation. An example of such an industry is petroleum extraction and transport. Companies in this industry achieve high levels of productivity and returns only by operating with massive capital investments (e.g. rigs and tankers). Equally, these capital investments are capable of generating substantial future liabilities - the Exxon Valdez incident is indicative of the scale of the liabilities that potentially can flow from these investments. The industry's response to these potential liabilities has not been to exit. Instead, all of the firms in the business of large scale extraction and transport have formed a syndicate to spread their risks across the entire industry. This insurance agreement is indicative of their commitment to the industry.

A firm that operates within region II ( $V^{\mathrm{so}}>0$, but $V^{\mathrm{L}}>V^{\mathrm{so}}$ ) is a socially benefical concern with a structure that presents the temptation for looting; firms in this region have mid-range values of capital productivity (other things being equal). The thrifts in the U.S. (prior to the revision of their regulatory structure) were good examples of such concerns. These firms had relatively low levels of capital intensity, due to lax regulation. In the absence of adequate oversight, the option of removing the assets and absconding prior to the arrival of the holders of the thrifts' liabilities (depositor) simply proved too great of a temptation. The savings and loans debacle that resulted involved the looting of assets in the region of US $\$ 140$ billion (see Akerlof and Romer (1993)).

Firms that operate in region III (in which $V^{\mathrm{SO}}<0, V^{\mathrm{L}}>0$ ) undertake activities that have negative net social worth. The combination of the technology of the industry and the institution of limited liability, however, generates incentives for shareholders to pursue the activity. All other things being equal, an industry with very low levels of capital productivity is a candidate. The classic example of such a "region III" enterprise was the toxic waste disposal business in the U.S. as it was operated prior to the adoption of the Resource Conservation and Recovery Act (RCRA). At that time it was the norm (due to the lack of regulation) to operate toxic waste disposal sites with little or no treatment or care. The typical operator of a dump site depended upon the waste containers and local geology to ensure that any liability arising from the dumping of waste occured well in the future. Virtually no capital was required, other than the land used as the dumping site, and very frequently this was merely leased for the term of the dumping operation. This behaviour and the liabilities it generated almost certainly rendered these operations of negative social value; but the deferral. of liabilities and the availability of liquidation in the interim made the operations financially attractive. This is looting at its clearest: the operations existed in these forms solely because of the availability of limited liability. It resulted in an estimated 10,000 orphaned waste sites and clean-up costs in excess of US\$100 billion to date (see Menell (1991)).

\subsubsection{The importance of sunk capital investments}

Capital is sunk when part of its value is lost in liquidation; this comes about primarily because the value of the capital is greater in its current use than in any other. The role of sunk capital is similar to, but distinct from, the role of capital productivity in determining the incentives of firms for looting. The distinction lies in the nature of the incentives provided for looting. The relative attractiveness of looting is determined by the difference between the benefits to be derived from remaining within the industry and the benefits from 
liquidating and leaving prior to the occurence of prospective liabilities. The previous sectiondiscussed one key determinant of this difference (the productivity of capital); this section discusses another: the costliness of liquidating capital (the cost of sunk capital).

A firm operating within region I in terms of the degree to which its capital is sunk will take decisions concerning liquidation in an optimal fashion. The value of the firm is tied to the industry within which it operates to too great an extent for liquidation to be an attractive option. An excellent example of such a characteristic is trade-name-based capital. Tradenames are capital items that are representative of the stock of goodwill attaching to the reputation of a firm, often representing a substantial proportion of firm value. ${ }^{10}$ Such assets are highly illiquid, in that they are valuable only within the context of the firm's current line of operations: there is some, but not substantial, value in British Airways marketing its own line food products, for example. For this reason, it would not be expected that firms which invest in the development of a trade-name would engage in significant amounts of looting the value of the asset would be largely lost on liquidation. By contrast a firm with a highly liquid capital stock is much more capable of undertaking "a hit and run strategy" of the nature of looting. For this reason many hazardous waste disposal firms had few assets specific to their industry. This allowed for maximum liquidity and placed them solidly within region III regarding their incentives to loot.

\subsubsection{The effectiveness of care expenditure}

The final factor of importance in determining the incentives for looting is the effectiveness of expenditure on damage avoidance. Its relevance lies in its capacity to close the gap between benefits and costs that creates the incentives for looting: effective care expenditure substitutes current (but lower) costs for future (but greater) damages. Highly effective expenditure will create incentives for the firm to undertake care, and will simultaneously remove the option to loot. In the context of toxic waste disposal, however, it would have been very difficult for firms to mitigate fully the future costliness of the waste. By their nature, chemical wastes must pass through one of three environmental media (organic, water or air) in their process of biodegradation (see Swanson and Vighi (1996)). Basic care expenditure in this industry is effective only in isolating and deferring, but not reducing, the ultimate accumulation of chemicals within these media. Most of the actions taken by toxic waste firms in the past (e.g. plastic or clay lining of pits) have been of this nature. These had virtually no mitigating effect, merely creating a larger loophole by extending the gap between receipt of benefits and occurence of costs. If, on the other hand, there had been a readily available low-cost method for treating these materials in a manner that actually reduced their ultimate costliness (by reducing the probability, and not merely deferring the timing, of the occurence of the damage), then these same firms may have been induced to undertake these measures in order to continue in the business.

\section{Policy implications of the incentives for looting}

In this section, the policy implications of the previous analysis are simply stated; see Mason and Swanson (1995) for a more complete discussion. The implications are two-fold, concerning first the nature of the industries which require regulation and, secondly, the

10 This is indicated by brand-name motivated mergers; moreover, recent changes in accounting principles have allowed for the incorporation of such assets within the balance sheets of most firms. 
forms of regulation that they require. Underlying the analysis is the institution of limited liability and the perverse incentives which it creates. In the absence of limited liability, neither the judgement proof nor the looting problem would exist. The first policy question therefore concerns whether limited liability should be retained as an institution - do its costs outweight its benefits (see Hansmann and Kraakman (1991))? This question is put to one side here, and limited liability will be taken as a given; the focus instead will be on the creation of new forms of regulatory institutions to complement existing liability systems.

It is important to note two things at the outset. First, the existence of looting as a distinct phenomenon requires separate regulation. The problem of excessive risk-taking by limited liability corporations, and the uncompensated risks that are thus created, has been analysed extensively (see, for example, Shavell (1986)). This is the rationale for the various ex post and retroactive forms of regulation that have been created to address e.g. the toxic waste problem: compensation, rather than the full regulation of the problem, has been the concern. The analysis of this paper (based upon the insight of Akerlof and Romer (1993)) indicates that there is a wholly distinct problem concerning the incentive under limited liability to create uncompensated costs, based upon a strategy that involves little or no risktaking. It is necessary to create regulatory policies focused solely upon this looting behaviour, since the two problems are distinct. ${ }^{11}$ Secondly, the policies to be developed must be ex ante in nature, directed to the prevention rather than the compensation of the problems arising from looting behaviour: refinements of ex post rules will not be enough.

What sorts of regulatory policies does the looting problem require? The analysis here indicates that the two necessary conditions for looting are : limited liability and long-term damages. Any industry in which limited liability holds and in which there is a large gap between the receipt of benefits and the occurence of liabilities is a candidate for the looting strategy. In this context, the industry characteristics that make looting the most attractive strategy have been outlined in the previous section: low capital productivity, low levels of sunk capital and low effectiveness of care expenditure. The presence of such conditions ensure that for a given project, the best return lies in the strategic liquidation of assets. These conditions indicate the nature of the policies that will be rquired to eliminate this socially costly strategy.

The first policy to consider is the requirement of mandatory insurance over a time horizon which matches that of the potential liability. ${ }^{12}$ This insurance must be provided in advance of incorporation, and extend beyond liquidation within industries deemed most likely to loot. Such an approach would substitute immediate (but smaller) payments in lieu of deferred (but greater) damages, and hence close the gap between benefits and costs that gives rise to looting. This is part of the approach adoptcd in the U.S., which has a thirty year financial responsibility undertaking (usually in the form of insurance) as a prerequisite to the licensing of waste facilities under RCRA.

11 For example, figure 3 shows that, if the social planner were to consider only the JP strategy, she would conclude that no regulation was necessary (beyond the system of strict ex post liability) for $\in$ less than 0.4 : both $V^{\text {So }}$ and $V^{\mathrm{SP}}$ are negative, and neither the social planner nor a shareholder pursuing a judgement proof strategy would choose to operate the firm. In the absence of regulation, however, looting firms will spring up to extract the positive value from the activity that such a strategy permits.

12 See Winter (1991) for a general overview of the issues involved in the liability insurance market, and particularly, the infeasibility of voluntary insurance for long-term liabilities. 
An alternative policy approach would be to close the gap in net benefits that renders the strategy profitable. Recall that it is the relative benefits to be derived from continuing in the business (capital productivity) compared to the benefits from its liquidation (damage avoidance less the costs of liquidity) that determines the profitability of looting. Policies may be directed to closing the gap between the benefits and the costs of remaining in business by, for example, the requirement that a bond be posted at the time of liquidation to cover any liabilities that may arise in the ensuing years. This policy would require the government to adopt a monitoring role in the liquidation of firms, assessing the nature of past operations and the prospects for future liabilities. The problem remains, however, that most firms that apply for liquidation are in fact already insolvent ; indeed, in the case of looting, they are so by design. For this reason the bond requirement must necessarily be imposed at the beginning of the life of the corporation, rather than at its liquidation. It then fulfills two functions: reducing the liquidity of assets and eliminating the gap between the receipt of benefits and the occurence of damages. ${ }^{13}$ The costliness of requiring substantial amounts of a firm's capital stock to be placcd in a non-working accounts as a bond points to another policy possibility: the establishment of minimum asset requirements and their auditing by the government. Minimum reserve and auditing requirements is precisely the form of regulation which governments have used to regulate the looting of banks (and it was very likely the relaxation of these requirements that led to the thrifts crisis in the U.S.). These reserve requirements are the analytical equivalent to a bonding regime, but one in which the assets are allowed to remain within the firm's working capital.

All of these policies indicate the importance of establishing minimum standards for incorporation. At present limited liability is available for a small fee and a minimum amount of legal work. Given that these corporations may then be used in combination with a looting strategy to generate substantial social losses (US $\$ 140$ billion in the thrifts crisis, at least US $\$ 100$ billion in the toxic waste clean-up in the U.S.), there is good reason to develop a regulatory regime for limited liability corporations so that they are not available on an unrestricted basis to minimally capitalised outfits in potentially damaging industries.

Finally it is interesting to note that there is another much more indirect approach to encouraging the vesting of firms within industries that generate potentially large and longterm liabilities. This indirect approach operates by making care expenditure more effective, rather than by making compensation more likely. The most heavy-handed way of accomplishing this is by technology-forcing, i.e. the mandating of care technology standards. This is how governments regulate many industries with the potential for generating long-term damages, e.g. food, drugs and cosmetics: in these industries, the levels of testing and certification required prior to public release are closely regulated. It could achieve the same ends less intrusively by investing in care technology as a public good, and then allowing its public release. Firms will be induced to accept this technology if it is available at low cost and it is effective at reducing (rather than merely deferring) damages.

${ }^{13}$ An editor of this volume has suggested that a bond requirement and mandatory insurance at actuarially fair rates would be equivalent. Our analysis suggests, however, that they will not in general be the same, due to the different roles that they play. The former is required only to increase the degree to which a firm's capital is sunk in the industry; the latter requires payment to cover the expected cost of damage caused by the firm's operation. 


\section{Conclusions}

The institution of limited liability makes financially attractive several additional strategies for operating an enterprise : asset stripping, subsidiarisation, and looting. The choice of strategy by a given enterprise is largely industry-dependent, determined by the characteristics of firms within that industry. This paper has demonstrated the attractiveness of the looting strategy for certain types of limited liability corporations. Solvency and liquidation are choice variables of the limited liability corporation, not stochastic events outside of its control. We have shown that when the question of solvency is endogenised (i.e. placed within the firm's control), there are a wide range of conditions under which the firm will select liquidation prior to the realisation of long-term liabilities as its most profitable option.

Looting has previously been used to describe the appropriation of assets under limited liability laws in the U.S. savings and loans crisis (see Akerlof and Romer (1993)). It is probably an even more apt description of the phenomenon that occurs in respect to hazardous waste site abandonment. Here the long-term liabilities associated with negligently managed wastes created the perfect opportunity for the exploitation of the limited liability loophole. This loophole will continue to generate similar strategic liquidation decisions in other industries of similar structure, until such time as it is closed by a general scheme of regulation designed to address this specific problem.

\section{REFERENCES}

AKERLOF, G. A. and ROMER, P.M., "Looting: The Economic Underworld of Bankruptcy for Profit", Brookings Papers on Economic Activity, 2, 1993, pp. 1-60.

BEARD, T. R., "Bankruptcy and Care Choice", Rand Journal of Economics, 21(4), 1990, pp. 626-34.

COOTER, R. D., "Economic Theories of Legal Liability", Journal of Economic Perpectives, 5(3), 1991, pp. 11-30.

HANSMANN, H. and KRAAKMAN, R., "Toward Unlimited Shareholder Liability for Corporate Torts", Yale Law Journal, 100(7), 1991, pp. 1897-1934.

MASON R. A. and SWANSON, T. M., "Long-term Liabilities and the Regulation of Looting", University of Cambridge Working Paper, 1995.

MENELL, P. S., "The Limitations of Legal Institutions for Addressing Environmental Risks", Journal of Economic Perspectives, 5(3), 1991, pp. 93-113.

POSEY, L. L., "Limited Liability and Incentives When Firms Can Inflict Damages Greater Than Net Worth", International Review of Law and Economics, 13(3), 1993, pp. 325-30.

RINGLEB, A. H. and WIGGINS, S. N., "Liability and Large-Scale, Long-term Hazards", Journal of Political Economy, 98(3), 1990, pp. 574-595.

ROE, M., "Corporate Strategic Reaction to Mass Tort", Virginia Law Review, 72(1), 1986, pp.1-59.

SCHWARTZ, A., "Products Liability, Corporate Structure, and Bankruptcy: Toxic Substances and the Remote Relationship", Journal of Legal Studies, 14, 1985, 689-750.

SEGERSON, K., "Liability Transfers : An Economic Assessment of Buyer and Lender Liability", Journal of Environmental Economics and Management, 25, 1993, pp. S-46-63.

SHAVELL, S., "The Judgement Proof Problem", International Review of Law and Economics, 6(1), 1986, pp. 45-58. 
SWANSON, T. M., "The Use of Liability Rule Systems to Regulate the Environment”, in Opschoor, J. B. and Pearce, D. W. (eds.), Persistent Pollutants: Economics and Policy, Kluwer Academic Publishers, Dordrecht, 1991, 183-195.

SWANSON, T. M. and VIGHI, M. (eds.), The Regulation of Persistent Chemicals: Economics, Institutions and Environmental Toxicology, Kluwer Academic Publishers, Dordrecht (forthcoming), 1996.

WIGGINS, STEVEN, N. and RINGLEB, A. H.,"Adverse Selection and Long-Term Hazards: The Choice between Contract and Mandatory Liability Rules", Journal of Legal Studies, 21(1), 1992, pp. 189-215.

WINTER, R. A., "The Liability Insurance Market", Journal of Economic Perspectives, 5(3), 1991, pp. 115-136. 